\title{
Domestically Acquired Legionnaires' Disease: Two Case Reports and a Review of the Pertinent Literature
}

\author{
Haluk Erdoğan, Hande Arslan \\ Department of Infectious Disease and Clinical Microbiology, Başkent University School of Medicine, Ankara, Turkey
}

\begin{abstract}
Background: Legionella species may colonize in home water systems and cause Legionnaires' disease (LD). We herein report two cases of sporadic LD associated with the solar energy-heated hot water systems of the patients' houses.

Case Report: A 60-year-old woman with chronic bronchitis and diabetes mellitus presented with a high fever, abdominal pain, and diarrhea. Physical examination revealed rales, and her chest radiograph showed a homogeneous density in the left lung. The Legionella urinary antigen test was positive, and an indirect fluorescent antibody test revealed a serum antibody titer of 1/520 for L. pneumophila serogroup 1 . In the second case, a 66-year-old man with diabetes mellitus was treated for pneumonia at another hospital. After the patient's general condition worsened and
\end{abstract}

he required mechanical ventilation, he was referred to our hospital. The Legionella urinary antigen test was positive. Neither of the patients had been hospitalized or travelled within the previous month. Both patients used hot water storage tanks heated by solar energy; both also used an electrical device in the bathroom to heat the water when solar energy alone was insufficient. The hot water samples from the residences of both patients were positive for $L$. pneumophila serogroup 1.

Conclusion: These cases show that domestic hot water systems heated by solar energy must be considered a possible source of community-acquired LD.

Keywords: Community-acquired infections, Legionnaires' disease, Legionella pneumophila, Legionellosis, pneumonia, solar energy
Legionella species are aerobic, gram-negative bacilli found in small numbers in aquatic environments. Legionellosis is a term used to describe any disease caused by Legionella bacteria and has two major forms: Legionnaires' disease (LD), a systemic infectious disease mostly involving the lungs, and Pontiac fever, an acute, febrile, self-limiting illness. Infection by Legionella bacteria is acquired by the aspiration of water or inhalation of aerosols containing the bacteria from environmental sources. Water temperature $\left(25-45^{\circ} \mathrm{C}\right)$, water stagnation, commensal microflora, and sediment accumulation are known to enhance the colonization of water distribution systems by Legionella species. More than 50 Legionella species have been identified to date. Legionella pneumophila serogroup (sg) 1 is the most common species and is responsible for $80-90 \%$ of cases of community-acquired LD. In epidemiological studies, $0.5-10.0 \%$ of cases of community-acquired pneumonia are attributed to Legionella. Although LD is often classified as an atypical pneumonia, clinical and laboratory findings do not help to distinguish LD from other causes of pneumonia. Therefore, the diagnosis of this infection requires specific diagnostic tests (1-3).

Stout et al. (4) investigated the presence of Legionella bacteria in the drinking water systems of 20 patients with community-acquired LD and showed that the source of infection was epidemiologically associated with drinking water in 8 patients. In another study, Castellani Pastoris et al. (5) reported that seroconversion against L. pneumophila sg 1 was found in three of the four family members; the father and daughter developed an influenza-like infection, but the son developed serious pneumonia. Legionella pneumophila sg 1 was present in the showerhead water and running water of the family's residence, as well as in the ventilation circuits of the refrigera-

This study was presented at the $24^{\text {th }}$ European Congress of Clinical Microbiology and Infectious Diseases, 10-13 May 2014, Barcelona, Spain.

Address for Correspondence: Dr. Haluk Erdoğan, Department of Infectious Disease and Clinical Microbiology, Başkent University School of Medicine, Ankara, Turkey Phone: +905056692459 e-mail: erdoganhaluk@hotmail.com

Received: 8 April $2015 \quad$ Accepted: 28 April $2015 \cdot$ DOI: 10.5152/balkanmedj.2016.150529

Available at www.balkanmedicaljournal.org 
tor located in the family's shop. Skogberg et al. (6) isolated $L$. pneumophila sg 6 from a 1-week-old infant with severe pneumonia; the same bacterium was isolated from the domestic water system of the infant's house. The family had been using boiled water as drinking water for the infant, but the infant was bathed twice after birth. These studies show that domestic water systems may be an important source of communityacquired LD. In this paper, we aim to increase the awareness of domestically-acquired LD.

\section{CASE PRESENTATION}

Both patients described in this paper provided written informed consent to publish their cases.

\section{Case 1}

A 60-year-old woman presented with a high fever, abdominal pain, diarrhea, nausea, and vomiting; she reported feeling imbalanced while walking, but denied having a cough or the production of sputum. The patient had visited our emergency department with the same complaints 2 days earlier. Her medical history included chronic bronchitis, type 2 diabetes mellitus, coronary artery disease, Hashimoto's thyroiditis, and smoking. She had no travel history during the previous month and had not been recently hospitalized. Her vital signs were as follows: body temperature $39.5^{\circ} \mathrm{C}$; heart rate 110 beats $/ \mathrm{min}$; blood pressure $110 / 60 \mathrm{mmHg}$; and respiratory rate $26 / \mathrm{min}$, with a $\mathrm{pO}_{2}$ of $91 \%$ on normal room air. Physical examination of her lungs revealed crepitant rales in the left basal zone. Her laboratory analysis revealed the following: leukocytosis $(15,900 / \mu \mathrm{L})$; C-reactive protein $>320 \mathrm{mg} / \mathrm{L}$; blood urea nitrogen $10 \mathrm{mg} / \mathrm{dL}$; creatinine 0.8 $\mathrm{mg} / \mathrm{dL}$; sodium $137 \mathrm{mmol} / \mathrm{L}$; phosphorus $2.2 \mathrm{mg} / \mathrm{dL}$; aspartate aminotransferase $30 \mathrm{U} / \mathrm{L}$; alanine aminotransferase $21 \mathrm{U} / \mathrm{L}$; and creatine phosphokinase $122 \mathrm{U} / \mathrm{L}$. Stool examination revealed leukocytes, but culture was negative for any bacterial pathogens. A chest X-ray revealed an increased density in the basal zone of the left lung (Figure 1). The Legionella urinary antigen test (BinaxNOW ${ }^{\circledR}$ Legionella Urinary Antigen Card; Alere, Inc., USA) was positive. An indirect fluorescent antibody test (Pasteur Cerba Laboratory, Saint-Ouen-l'Aumône, France, forwarded by Duzen Laboratories, Ankara, Turkey) revealed a serum antibody titer of 1/520 for L. pneumophila sg 1 . Starting on the day of admission, $500 \mathrm{mg}$ of levofloxacin (Tavanic; SanofiAventis) was administered intravenously every 12 hours. The fever diminished on the fifth day of admission, and the patient was discharged on the seventh day.

The patient lived in an apartment on a site containing two high-rise buildings in Alanya, Turkey. Many of the buildings remained closed for most of the year. The water system used the local city water supply, and hot water was produced by a central solar heating system (Figure 2). When the hot water supply was insufficient, the water was heated in the bath-

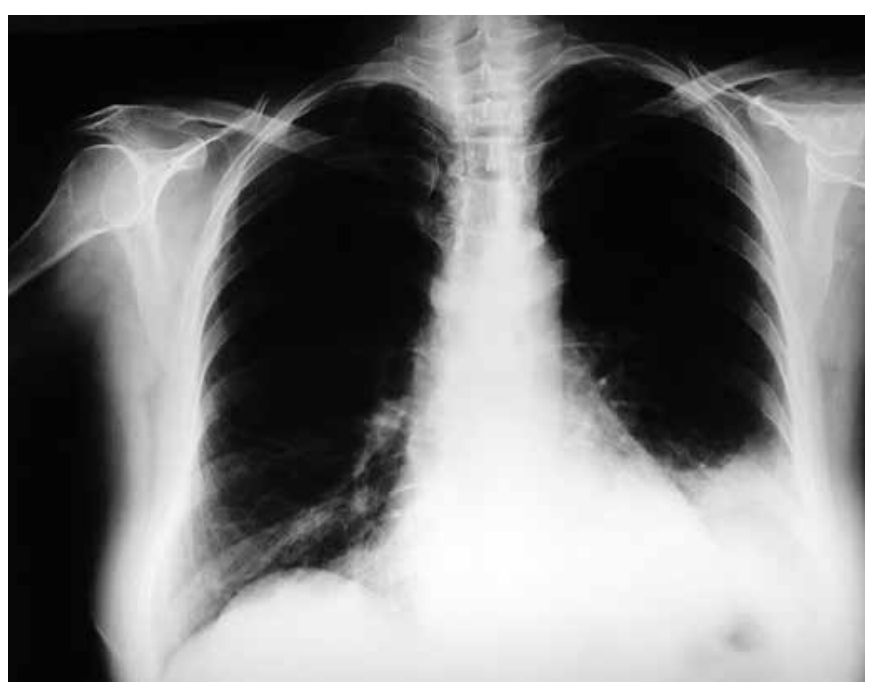

FIG. 1. Chest radiograph of Patient 1, showing an infiltrate in the left lower zone

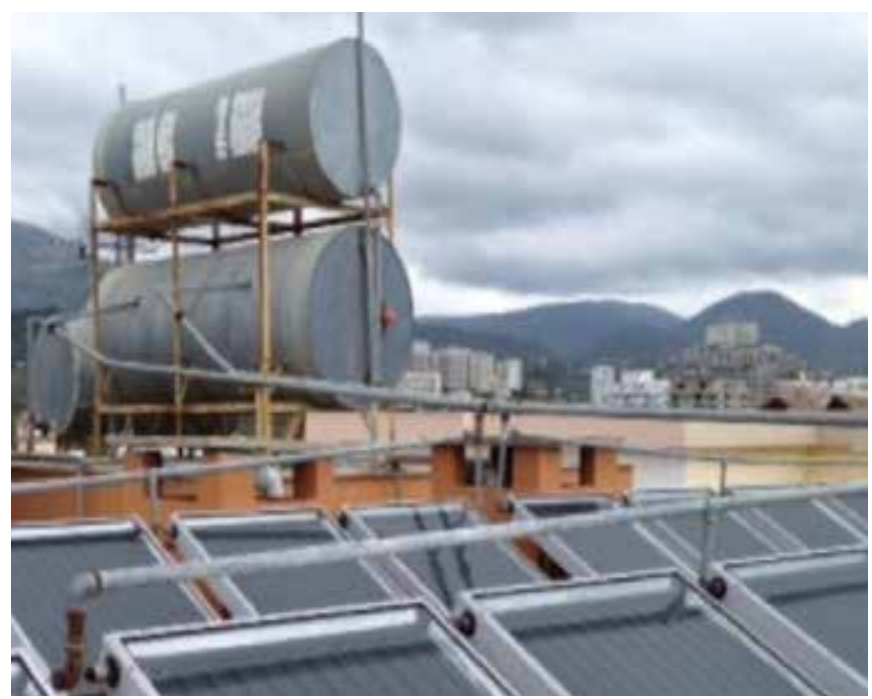

FIG. 2. Hot water storage tanks supplied by a central solar heating system in the block of Patient 1

room with an electrical heating device (instantaneous water heater). Hot water samples from the solar heating tank and showerhead and cold water samples from the tap were collected in $1000 \mathrm{~mL}$ sterile containers after the water had drained for 15 to 30 seconds. The hot water samples were not hot, and free chlorine was not measured. These samples were concentrated by membrane filters with a pore size of $0.2 \mu \mathrm{m}$ (Sartorius AG, Göttingen, Germany), and heat treatment was used to reduce the numbers of other microorganisms in the samples before spreading the water samples on buffered charcoal yeast extract alpha (BCYE- $\alpha$ ) agar plates and glycinevancomycin-polymyxin-cycloheximide (GVPC) agar plates. The suspected colonies were identified by a Legionella latex agglutination test (DR0800M; Oxoid, UK). Cultures of the hot water samples showed the growth of L. pneumophila sg 1; the colony count was 10 to 100 colony-forming units $/ \mathrm{mL}$ in 
these samples. The patient lived with her husband in the same residence; however, he had no symptoms or complaints. After the Antalya County Health Department was informed about this case, Legionella decontamination of the building's water system was managed by implementation of hyperchlorination and superheating $\left(>60^{\circ} \mathrm{C}\right)$ of the water.

\section{Case 2}

A 66-year-old man with diabetes mellitus was treated for community-acquired pneumonia in a private hospital. The patient was referred to our hospital after failing to respond to beta-lactam antibiotic therapy and developing respiratory insufficiency. He was a smoker, had no travel history, and had not been hospitalized prior to the pneumonia. Physical examination revealed a body temperature of $36^{\circ} \mathrm{C}$, pulse rate of $98 / \mathrm{min}$, and blood pressure of 110/70 $\mathrm{mmHg}$. Bilateral lung rales were present. Blood analysis showed the following: leukocytosis $(27,000 / \mu \mathrm{L})$; C-reactive protein $220 \mathrm{mg} / \mathrm{L}$; blood urea nitrogen $46 \mathrm{mg} / \mathrm{dL}$; creatinine $1.4 \mathrm{mg} / \mathrm{dL}$; sodium $139 \mathrm{mmol} / \mathrm{L}$; aspartate aminotransferase $84 \mathrm{U} / \mathrm{L}$; and alanine aminotransferase 102 U/L. Sputum analysis of a deep tracheal aspirate revealed 8 to 10 leukocytes and 5 to 6 epithelial cells. Gram staining showed no predominant bacteria, and there was no growth on the sputum culture. The Legionella urinary antigen test (BinaxNOW ${ }^{\circledR}$ ) was positive, but pneumococcal urine antigen was negative. A posteroanterior chest X-ray revealed diffuse patchy infiltration (Figure 3). Thoracic computed tomography showed bilateral advanced emphysematous changes, irregular parenchymal consolidation of the superior segments of the lower lung lobes, and minimal pleural effusion of the left hemithorax. Intravenous ciprofloxacin at $1200 \mathrm{mg} /$ day (Cipro; Bio Farma) and clarithromycin at $1 \mathrm{~g} /$ day (Klacid; Abbott Laboratories) were started. The patient was disconnected from the mechanical ventilator on the $7^{\text {th }}$ day and discharged on the $18^{\text {th }}$ day of admission.

The patient lived in a rental house in Anamur, Turkey and was using the local city water supply as the water source. The hot water was supplied by a solar heating system and the tank on the roof of the building, both of which were older than 10 years in age (Figure 4). When solar energy was insufficient, an instantaneous electrical water heater in the bathroom was used to heat the water. Hot water samples were taken from the tank, the solar heating system running to the bathroom and the showerhead, as well as cold water samples from the tap, for culture. The hot water samples were not hot, and free chlorine was not measured. In all water samples except the cold water sample, L. pneumophila sg 1 was isolated. The colony count was 10 to 100 colony-forming units $/ \mathrm{mL}$. The patient lived with his wife in the house; however, she had no symptoms or complaints. The old tank and solar heating systems were replaced with new ones after this case.

\section{DISCUSSION}

These two case reports show that community-acquired LD can easily be overlooked. Therefore, clinicians should be

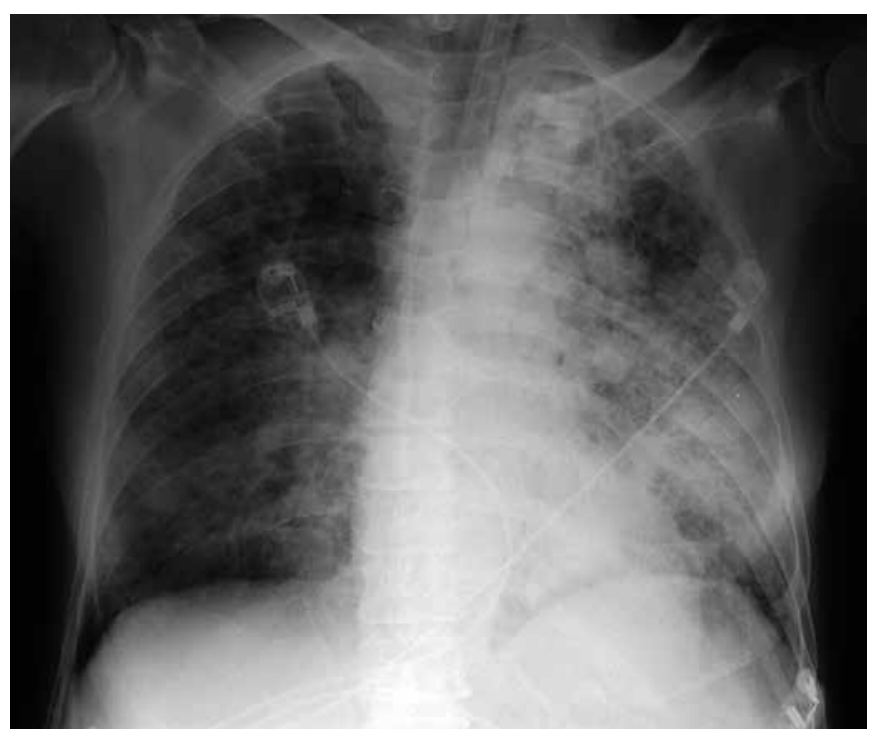

FIG. 3. Chest radiograph of Patient 2 , showing patchy, bilateral pulmonary infiltrates

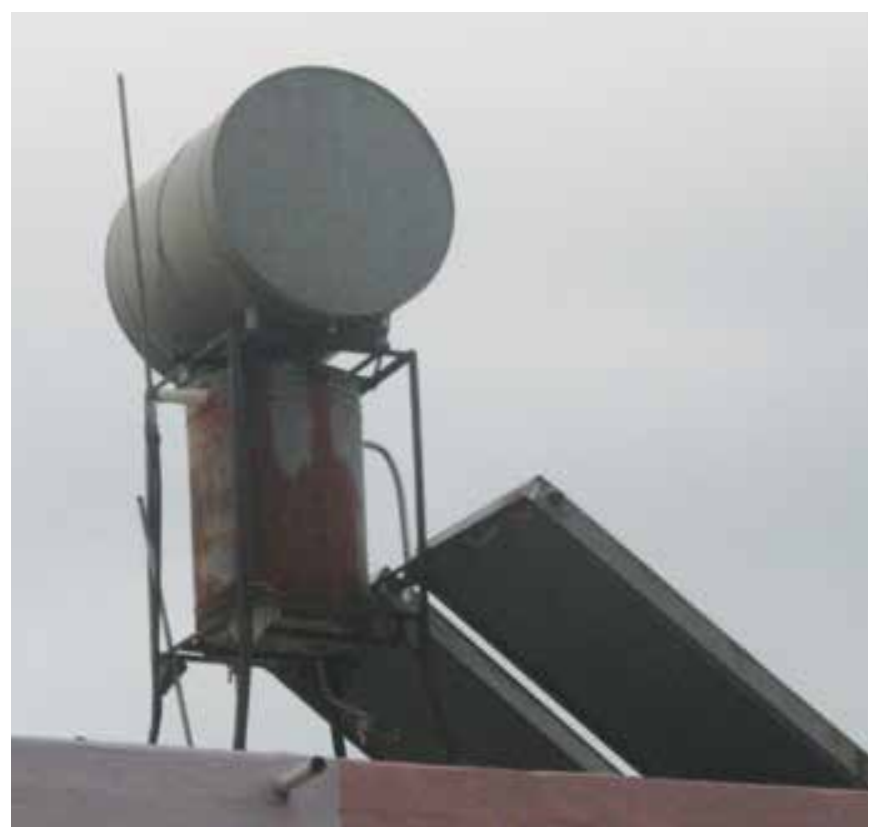

FIG. 4. The old solar heating systems in the house of Patient 2

aware of LD in patients with community-acquired pneumonia with the presence of extra pulmonary involvement and those with risk factors for LD. Both of our patients had risk factors such as an underlying chronic illness, smoking, and older age. In patients with no history of recent hospitalization or travel, the domestic water system must be considered the source of infection in patients with LD.

The infective dose of Legionella in humans is unknown. The environmental concentration of Legionella might vary according to sampling and analytical techniques. Moreover, protozoa have been shown to release vesicles containing nu- 
merous Legionella bacteria, and these vesicles can cause LD (2). Person-to-person transmission has never been reported. In our patients, the main diagnostic method was urinary antigen detection; a high antibody titer was detected in one patient. The absence of a history of travel and hospitalization during the incubation period plus the isolation of $L$. pneumophila sg 1 from the patients' homes focused our attention on the solar heating systems. Taken together, these findings indicate that both cases of LD were most likely domestically acquired.

Colonization of Legionella species in domestic hot water systems has been found in $6.0 \%$ to $32.7 \%$ of cases in various studies (7-9). Alary and Joly (7) searched for Legionella bacteria in 211 domestic water systems, and $69(32.7 \%)$ houses had at least one positive sample. While Legionella was not detected in the houses with a gas or oil water heater, bacterial growth was present in the water samples of houses with an electrical heating system. The authors concluded that the houses that were located in old residential districts, used old water heaters, and had low water temperature were the underlying risk factors (7). Stout et al. (8) identified Legionella in $6 \%$ of water samples from 218 domestic water systems. They found a significant correlation between low water temperature of the hot water tanks and isolation of the bacteria (8).

Solar energy utilization for domestic hot water is increasing worldwide. During periods of low sunlight, solar thermal heating systems can warm the water to support the growth of Legionella. In particular, old storage tanks may have a biofilm or structural defects that limit water circulation, potentially increasing the risk of Legionella colonization. The hot water storage tank in the first case described herein was not drained from the bottom; instead, it was drained from the middle of the tank, resulting in an area of stagnation. Part of the water system was also used only intermittently. In the second case, the house was a single-family residence, and both the hot water tank and solar heating system were old. In both houses, water from the solar heating system running to the bathroom was heated with an electrical heating device (instantaneous water heater). Mathys et al. (9) reported that hot water systems using solar energy to supplement conventional hot water supplies have lower temperatures than conventional systems in single-family residences. In another study, Mouchtouri et al. (10) found Legionella colonization in $17 \%$ of Greek hotel water systems heated by solar energy. Therefore, to prevent growth of Legionella bacteria, the temperature of the water in domestic water tanks must be raised to a high enough temperature and appropriate maintenance of the entire system must be performed regularly.

The limitation of our study was that Legionella species were not cultured from the patients. Therefore, we were not able to determine the clonality of the environmental strains and the patients' infectious agents.

In conclusion, LD must be considered in patients with community-acquired pneumonia who use domestic hot water systems heated by solar energy systems, which may be a source of this infection.

\section{Ethics Committee Approval: N/A.}

Informed Consent: Written informed consent was obtained from patients who participated in this study.

Peer-review: Externally peer-reviewed.

Author Contributions: Concept - H.E., H.A.; Design H.E., H.A.; Supervision - H.E., H.A.; Resource - H.E., H.A.; Materials - H.E., H.A.; Data Collection and/or Processing - H.E., H.A.; Analysis and/or Interpretation - H.E., H.A.; Literature Search - H.E.; Writing - H.E.; Critical Reviews - H.E., H.A.

Conflict of Interest: No conflict of interest was declared by the authors.

Financial Disclosure: The authors declared that this study has received no financial support.

\section{REFERENCES}

1. Phi N, Parry-Ford F, Harrison T, Stagg HR, Zhang N, Kumar K, et al. Epidemiology and clinical management of Legionnaires' disease. Lancet Infect Dis 2014;14:1011-21. [CrossRef]

2. Obrien SJ, Bhopal RS. Legionnaires' disease: the infective dose paradox. Lancet 1993;342:5-6. [CrossRef]

3. Marston BJ, Plouffe JF, File TM Jr, Hackman BA, Salstrom SJ, Lipman HB, et al. Incidence of community-acquired pneumonia requiring hospitalization. Results of a population-based active surveillance Study in Ohio. The Community-Based Pneumonia Incidence Study Group. Arch Intern Med 1997;157:1709-18. [CrossRef]

4. Stout JE, Yu VL, Muraca P, Joly J, Troup N, Tompkins LS. Potable water as a cause of sporadic cases of community-acquired Legionnaires' disease. $N$ Engl J Med 1992;326:151-5. [CrossRef]

5. Castellani Pastoris M, Viganò EF, Passi C. A family cluster of Legionella pneumophila infections. Scand J Infect Dis 1988;20:489-93. [CrossRef]

6. Skogberg K, Nuorti JP, Saxen H, Kusnetsov J, Mentula S, Fellman V, et al. A newborn with domestically acquired Legionnaires' disease confirmed by molecular typing. Clin Infect Dis 2002;3:e82-5. [CrossRef]

7. Alary M, Joly JR. Risk factors for contamination of domestic hot water systems by legionellae. Appl Environ Microbiol 1991;57:2360-7.

8. Stout JE, Yu VL, Yee YC, Vaccarello S, Diven W, Lee TC. Legionella pneumophila in residential water supplies: environmental surveillance with clinical assessment for Legionnaires' disease. Epidemiol Infect 1992;109:49-57.

9. Mathys W, Stanke J, Harmuth M, Junge-Mathys E. Occurrence of Legionella in hot water systems of single-family residences in suburbs of two German cities with special reference to solar and district heating. Int J Hyg Environ Health 2008;211:179-85. [CrossRef]

10. Mouchtouri V, Velonakis E, Tsakalof A, Kapoula C, Goutziana $\mathrm{G}$, Vatopoulos A, et al. Risk factors for contamination of hotel water distribution systems by Legionella species. Appl Environ Microbiol 2007;73:1489-92. [CrossRef] 